\title{
Da alienação à interpretação - os usos da ironia
}

Cecily O’Neill*

Trad.: Biange Cabral

De acordo com o dicionário ironia consiste em se dizer uma coisa para significar o oposto. Quando usamos a ironia, nós transmitimos uma mensagem de tal maneira ou em tal contexto que evocamos uma resposta que envolve uma re-interpretação de nosso significado. Eu espero mostrar que uma abordagem irônica no desenvolvimento do process drama ${ }^{1}$ conduz nossos alunos ao universo da ficção, os desafia a uma resposta ativa, e promove julgamentos e interpretações.

Ironia é um conceito que resiste a definições fáceis. É necessário estar alerta à sua presença para compreender como ela opera. Um conhecido meu estava parado na porta de casa com sua filha de quatro anos, olhando a chuva. "Outro lindo dia de verão inglês!", ele disse. A menina ficou intrigada e ele tentou explicar a ela o conceito de ironia. Afinal, ele era um professor e um acadêmico! Um pouco mais tarde, ela o tomou pela mão e o conduziu até o seu quarto. Seus brinquedos e roupas estavam artisticamente espalhados pelo quarto. "Olha papai, que quarto bem arrumado!”, ela disse com satisfação. Ela havia compreendido que o contexto é importante para detectar a presença da ironia. Isto é o que faz com que seja difícil prover exemplos fora de contexto. Suponhamos que eu esteja me comportando de forma pretensiosa e auto-apreciativa, e um amigo, ou talvez um inimigo, diga que eu sou tão modesto quanto bonito. Pode levar um momento ou dois para cair a ficha e para que eu entenda a mensagem.

O conceito de ironia tem sido considerado "vago, instável e multiforme”, e mais de uma dúzia de diferentes categorias foram identificadas. Nós podemos suspeitar da presença de ironia quando uma peça ou um episódio dramático contém contradições, ambigüidades, incongruências, falas enganosas, absurdos e reversões. Os pontos altos da ironia no drama clássico são familiares. Em Júlio César, Marco Antônio insiste que os assassinos de César são todos "homens honrados". Quando ele é pressionado a ler o testamento de César para o povo, ele se deixa persuadir e sua ironia é evidente: "Eu temo ter sido enganado pelos homens honrados cujos punhais esfaquearam César; eu realmente temo”.

Lady Macbeth dá as boas vindas a Duncan em sua casa onde ela planeja matá-lo: "Ele que está vindo, deve ser bem recebido"; o honesto Iago adverte Otelo: "Oh, esteja atento meu senhor, com o ciúme, 'este monstro de olhos verdes', enquanto destruía sua confiança

* Cecily O’Neill é uma autoridade mundial no campo do Drama na Educação. Seu atual foco de trabalho é o process drama, uma parte essencial do teatro contemporâneo. Profere palestras e conduz workshops com estudantes, professores, diretores e atores em vários países, dividindo seu ano acadêmico entre Londres e Estados Unidos, onde é Professora Associada na Universidade Estadual de Ohio. É Artista Associada do Teatro Unicórnio.Entre seus livros destacam-se: Dorothy Heathcote: Collected Writings on Education and Drama, Drama Structures and Drama Guidelines, Drama Worlds - a framework for process drama. É editora das séries populares da Harpercollins: Plays Plus, Classics Plus e Short Plays Plus. 
em Desdêmona, e nós, os espectadores, apreciamos o sentido de reconhecimento quando percebemos o significado real subjacente a estas palavras e ações. A ironia é um dos mais poderosos meios de colocar em ação aquilo que States (1971, xvi) denominou "o mecanismo de produção de tensão vital da ação dramática”

A ironia representa um papel significativo na comédia e na tragédia. Com incongruência cômica os camponeses irlandeses em O Playboy do Mundo Ocidental rejubilam-se com o fato de que a menina Pegeen Mike "estará salva esta noite com um homem que matou seu pai, afastando o perigo da porta”. Lady Bracknell em A Importância de Ser Honesto está interrogando o noivo de sua filha sobre suas origens. Ela pergunta se ele nasceu sob "o púrpura do comércio" ou o "rosa da aristocracia”. Finalmente ela se volta "para assuntos de menor interesse". "Seus pais estão vivos?" "Sinto muito, lady Bracknell, mas perdi ambos meus pais". "Perder um dos pais pode ser considerado um azar; perder ambos já parece falta de cuidado". Este tipo de distanciamento, em um tom quase caloroso, é típico da atitude irônica, e toda a cena, na realidade toda a peça, é uma escala ascendente de ironias.

Mas a ironia não é apenas uma questão verbal. No drama ela é também estrutural. Desde que Édipo, pela primeira vez, trouxe uma terrível maldição para si próprio, a ironia tem sido a alavanca do efeito dramático, levando-nos a desenvolver expectativas que certamente

Serão revertidas

É a minha prece solene ...

Se com meu conhecimento, casa ou coração

Receber o homem culpado, sobre minha cabeça

Morram todas as maldições que tenha lançado aos outros.

O resto da peça tem a ver com o desenrolar dessas maldições. No drama irônico nós podemos estar certos de que sempre que promessas solenes são feitas, votos proferidos ou maldições declaradas, veremos que serão quebrados da pior maneira ou podemos esperar seu retorno sobre a cabeça daquele que fez o juramento. Nós podemos antecipar os mais extremos revezes da fortuna para os personagens no drama.

Alguns comentaristas vão mais longe e dizem que todo drama é um gênero essencialmente irônico, porque se concentra na impessoalidade e na representação. Mas nem tudo que difere daquilo que parece é um caso de ironia, nem o é cada vez que dizemos uma coisa para significar outra. Na ironia, o relacionamento entre aparência e realidade revela-se como um contraste, uma oposição, um paradoxo, uma incongruência ou uma contradição - ela ativa uma série interminável de interpretações subversivas. É uma técnica de dizer muito pouco e significar tanto quanto possível. A ironia evita a declaração direta e emprega uma atitude objetiva e desapaixonada, permitindo investigar e iluminar questões poderosas e controvertidas.

Eu me dei conta, inicialmente, de que a ironia era um elemento de valor inquestionável para estruturar o processo dramático quando comecei a perceber seus padrões no meu próprio ensino e no de outros. Surpreendi-me ao perceber que quando uma sessão de drama saía bem, um dos fatores da sua eficácia parecia estar no tipo de armadilha irônica

U 8 - Dezembro 2006 - No 8 
em que os participantes eram pegos. Ao definir uma situação que estava fadada a evocar uma resposta negativa dos alunos, eu comecei a entender que, ao se oporem às limitações da situação, eles estavam de fato aceitando o drama. Por exemplo, no papel de Ministro da Educação, com uma classe de 14 anos no papel de educadores eminentes, eu anunciei que no futuro todos os que tivessem entre 16 e 18 anos iriam ser educados em instituições especiais, isolados de suas famílias, e não retornariam para casa por dois anos. Apresentei isso como um desenvolvimento inovador e sob uma luz mais vantajosa. Afinal, o projeto iria possibilitar uma imersão real na educação, iria afastar os alunos das tentações da rua e outras distrações, proporcionando-lhes um treinamento moral e físico intenso. Tratava-se de uma prática que as crianças mais privilegiadas vinham apreciando por anos seguidos em internatos de elite. No papel de educadores, os alunos tinham que aceitar a situação, mas como jovens de 14 anos, eles resistiram a ela com toda convicção. Dorothy Heathcote descreve o irresistível mecanismo que leva a este tipo de resposta:

"o poder mais elementar a ser dado aos outros é o de discordar do papel, apontando a fraqueza na posição daquele papel, ou mesmo se opondo ao papel ... oposição a um papel coloca a classe numa posição segura para discordar, estabelecendo seu direito de se opor ao poder do professor"

O tipo de resistência provocado não é necessariamente uma oposição grosseira. A primeira vez que trabalhei com Heathcote, ela armou uma armadilha para o grupo em um contexto absurdo, o que nos impediu de expressar resistência. Nós descobrimos que éramos pessoas que haviam concordado em ter nossos pés removidos. Sob sua orientação, nós exploramos as implicações positivas desse estado físico. Todos os aspectos negativos foram mantidos à distância, enquanto celebrávamos nossa condição de estar sem pés. O objetivo de Heathcote era abalar nossa fixação na lógica adulta, treinando-nos para aceitar e explorar idéias aparentemente bizarras ou absurdas. Esta aceitação, este "dizer sim" a uma situação sem saber onde ela nos levaria, é o coração de cada drama, além de ser essencial à ampliação da improvisação.

A ironia nos provê de uma capacidade ilimitada de negar ou se opor a idéias. É esse aspecto que a torna de grande valor, tanto para o dramaturgo quanto para o professor. Ela permite que estabeleçamos estruturas para o debate dentro dos parâmetros do tópico ou tema, como uma forma de levantar questionamentos ao invés de fornecer respostas. É uma técnica para lidar com conceitos, uma metodologia, um meio complexo de apresentar idéias para a investigação e a oposição.

Um texto dotado de uma ironia devastadora, como A Modest Proposal (Uma Proposta Modesta), de Jonathan Swift, não é um texto dramático, mas é sob todos os pontos de vista uma impersonação, na qual Swift torna-se aquilo que ele contesta. Nesta proposta fria, cuidadosamente argumentada e lógica, ele oferece um remédio para os males da pobreza e da superpopulação entre os católicos irlandeses que viviam pior que o gado de seus senhores ingleses ausentes. Sua proposta inteiramente racional, ainda que completamente desumana, é a de que esses latifundiários deveriam comprar e comer a carne fresca dos 
bebês dos despossuídos. Se essa estratégia econômica fosse colocada em vigor, argumenta ele, as crianças não seriam mais uma carga para seus pais, mas uma fonte de renda. Elas seriam procriadas, criadas, abrigadas e alimentadas pelo menos tão cuidadosamente quanto outros animais domésticos, e as indústrias a isto relacionadas gerariam empregos, tais como a curtição de suas peles e a manufatura de delicadas luvas para senhoras. Na medida em que antecipa com entusiasmo a beleza e utilidade de seu esquema, ele ainda recomenda métodos de cozimento (preparação de alimentos):

"Quanto a nossa cidade de Dublin, casas de abatimento podem ser apontadas e açougueiros não serão necessários, embora eu recomende, em vez disso, que se comprem crianças vivas e as preparem para a faca, como se faz com os porcos a serem assados”. Qual a melhor maneira de cozinhar bebês?"

A indignação selvagem de Swift para com os males sociais da Irlanda do século XVIII é transformada em complacência com a modesta proposição de uma solução humana para a prole, a qual lhe permite expor estes males ao pretender redirecioná-los. $O$ frio distanciamento de sua declaração sustenta grande parte do horror do texto, criando grande impacto emocional sobre o leitor.

\section{Detectando a Ironia}

Como reconhecer a presença da ironia no discurso ou no drama? Podem não existir sinalizações óbvias para indicar que ela está presente, ficando para nós todo o trabalho de detecção e interpretação quando tentamos inferir o significado real da mensagem a partir daquilo que é dito, da maneira como é dito, quem está dizendo e em que contexto. Quintiliano, nas Instituições Oratórias, alega que a ironia pode ser evidenciada na maneira como é expressa, no caráter do orador e pela natureza do assunto. A atitude irônica requer que o escritor ou o orador esteja, pelo menos em algum grau, assumindo um papel. Isto é certamente verdade no processo dramático. Nossa sinalização pode indicar que nós podemos não estar exatamente querendo significar o que estamos dizendo; os papéis que nós escolhemos representar podem convidar à interpretação, à re-apreciação e à rejeição; ou a natureza do assunto em si pode indicar que nosso ponto de vista é irônico.

Se a intenção do autor/personagem não foi compreendida como irônica, ele pode ser apontado como portador de pontos de vista opostos àquilo que foi pretendido. Recentemente, um político britânico deplorou 'o povo horrível que se encontra em transportes públicos'. Ele estava, na verdade, parodiando as opiniões de seus opositores, e estava, de fato, apoiando a melhoria do transporte público, mas a intenção irônica de sua declaração foi mal compreendida e ele foi transformado em vilão pela mídia.

É possível que nunca haja acordo completo sobre quando a ironia está vigorando e esta ambigüidade salienta um sentido de desconforto produtivo, uma urgência para ler a situação em maiores detalhes. Em um meio dominado pelo feminismo, se eu montar um texto chamado "Escola de Esposas", eu posso assumir que uma perspectiva irônica será reconhecida. O ponto de partida pode ser o fato de que eu sou uma mulher. Poderia não ser 
aceitável que um colega homem adote tal perspectiva. O plano de aula "The Starship" (A Nave Espacial) em Drama Structures, é um bom exemplo desta dificuldade da apresentação. Um professor, no papel de uma criatura que se recusa a acreditar que homens possam ser oficiais de uma nave espacial, deverá sinalizar isso com muito cuidado, se quiser criar um contexto irônico para explorar os efeitos da discriminação de gênero.

\section{Como a Ironia Funciona}

A forma mais útil de ironia em processos dramáticos é, sem dúvida, a da situação irônica, onde operam compromissos ocultos, objetivos são disfarçados e expectativas revertidas. Quanto mais econômicos formos na determinação de um contexto irônico para oposição e reconstrução, mais eficaz ele será. O objetivo é atingir o máximo de plausibilidade para o significado aparente e o máximo de convicção para os papéis que desempenhamos para estabelecer o contexto, enquanto usamos o menor número possível de sinalizações para indicar o significado real.

Um exemplo familiar do tipo de conspiração irônica é a aula "Casa Assombrada" descrita em Drama Structures. A personalidade da Sra Brown corporifica todo o desconforto que os participantes sentem ao aceitar seu convite para passar uma noite em Darkwwod House. Seu ponto de vista, negando a existência de fantasmas, ao mesmo tempo em que dá pistas sobre o "não mencionável", convida a um "não" imediato. Ainda que, embora desconfiando de sua proposta e exigindo outras garantias, o grupo está inevitavelmente dizendo "sim" à situação dramática. Em algumas versões dessa aula, a ironia é reduzida ao se substituir a tarefa original, a qual é de interpretação e reconstrução, por outra menos ambígua, com tarefas que exigem menos. O prazer nesta aula reside em descobrir os motivos reais da Sra Brown e flagrá-la no processo de ludibriar.

Os alunos mais jovens tendem a desconsiderar a ironia e encarar diretamente a situação. A sra Brown é geralmente considerada inocente e vítima dos moradores da cidade. Uma criança de 8 anos ficou convencida que o médico da localidade era o vilão da peça, e que ele queria herdar a casa. A professora concordou com essa interpretação e criou dois testamentos: o verdadeiro e outro forjado pelo médico. Interpretar a ironia ou mesmo reconhecer sua presença requer compreender a linguagem e ter alguma familiaridade com as convenções dramáticas. Mesmo a criança mais brilhante pode não ter a experiência necessária para reconhecer e interpretar um convite irônico.

Tão logo uma voz irônica seja identificada pelos participantes de um processo dramático, estes começam a ter prazer em executar as tarefas e apreciar os resultados. A voz irônica, a impersonação, a qual pode ser econômica e eficazmente produzida pela função dramática assumida pelo professor (teacher-in-role), torna-se uma parte significante do controle do contexto. Em "Space Traders" (Comerciantes do Espaço), uma aula recente ministrada por Brian Edmiston, o contexto dramático se referia a um lugar onde o remédio proposto para sanar os males sociais era enviar os desempregados e elementos não desejáveis da sociedade para um outro planeta, em troca de ganhos financeiros. A satisfação dos participantes esteve em reconhecer, debater e resistir às exigências deste contexto, estando dentro dele. 
A primeira resposta ao reconhecimento da ironia, à constatação de que as coisas não são o que parecem, é um retumbante "não". A ironia provoca um choque de reconhecimento negativo. Inicialmente, e paradoxalmente, uma atitude irônica leva à descrença. Como nos exemplos que citei, ao recusarmos a aceitar o que nos é oferecido no contexto irônico, nós começamos a aceitar e acreditar no drama. Nós nos opomos ao que é oferecido no âmbito da ironia, ainda que o drama nos convide a aceitar e concordar com ele. A fim de tomar parte numa experiência nós precisamos colidir com sua proposição. Esta aceitação modificada exige um estado de alerta, um distanciamento, um tipo de alienação, seguida pela busca de interpretações alternativas e soluções. O drama é "uma investigação da armadilha em que o mundo tornou-se" .

Um ponto de vista irônico nos desacomoda, não porque ele caçoa ou ataca, mas porque ele nega nossas certezas expondo o mundo como uma ambigüidade. $O$ mundo irônico é aberto para a contemplação, a investigação, o julgamento e a transformação. Eu ainda lembro vivamente de uma sessão de capacitação para professores em drama, liderada por Geoff Gilham, na qual o grupo, como cidadãos, era forçado, para o bem do Estado, a construir um muro em volta da cidade. Essa era uma tarefa difícil, mas iria garantir sua segurança futura. Após muito trabalho, a tarefa foi completada. Então o grupo ficou sabendo que a política havia mudado. $\mathrm{O}$ muro não era mais necessário. As ordens para sua demolição vieram do líder. Uma vez que era do interesse do Estado, a demolição ocorreu imediatamente, e aí o grupo recebeu ordens para reconstruí-lo. Embora isto tenha ocorrido há 20 anos, eu nunca esqueci o intenso choque de alienação e reconhecimento que esta alegoria causou - um impacto que foi tanto intelectual quanto emocional. Não foi necessária nenhuma explicação ou comentário pelo líder. Como diz Brecht, as leis sociais sob as quais nós estávamos interpretando saltaram à vista. ${ }^{3}$ A lição é que o dramaturgo ou o professor de drama, trabalhando sob uma perspectiva irônica, não precisa tentar resolver os mistérios do mundo irônico ou curá-los de alguma maneira. ${ }^{4}$ Esta é uma tarefa para os participantes ou para os espectadores, aqueles que "lêem" suas ironias e interpretam suas ambigüidades.

Um aspecto fundamental do método do drama é que a ironia deve permanecer implícita durante o evento. "Implícito" deriva-se da palavra latina correspondente a "guardado", e é um termo que Bolton tem utilizado de uma forma muito útil para esclarecer a estrutura do drama. ${ }^{5}$ Onde há uma intenção irônica, é deixado aos participantes preencher as lacunas, completar as charadas, e traçar as analogias. A implicação é que isto leva os participantes à aceitação do evento e à colaboração mental. Há um elemento de quebra-cabeça que precisa ser solucionado. Os participantes, em busca de soluções, repetem o processo da invenção, tornando-se co-autores do trabalho.

Como decorrência, tanto o engajamento quanto a interpretação ativa emergem, e a ironia cria aquilo que Boots já chamou de "amáveis comunidades de reconhecimento comum”. Os participantes tornam-se espíritos cordatos junto aos espectadores, formando uma rede de conluio. Esta comunidade luta com as tarefas comuns de identificação, discriminação e reconhecimento, necessários para expor a conspiração irônica no centro do processo dramático. 


\section{A Atitude Irônica}

Encontrada em conversas, numa página ou numa performance, a ironia sempre provoca a adoção simultânea de dois conjuntos mentais diversos, um tipo de dupla exposição. Nenhum é inteiramente assimilado pelo outro, mas ambos são mantidos em uma tensão dinâmica. Nós somos atingidos pela retórica de Marco Antônio, enquanto sabemos que Brutus é, de fato, um homem honrado. Em Édipo Rei, nós compreendemos as tentativas de Édipo para livrar Tebas da praga a partir de seu ponto de vista, mas nós julgamos o que ele diz segundo um ponto de vista bem distinto. Nós interpretamos suas palavras exatamente com o significado que ele lhes atribui, mas ao mesmo tempo nós desenvolvemos interpretações sobre seu significado. A ironia inevitavelmente mina nosso envolvimento não racional com a ficção e evoca esta resposta complexa, recolocando a submissão à experiência através de uma maior consciência de seu significado.

Tão logo um personagem diga uma coisa para significar outra, uma impressão dupla surge na mente dos espectadores e participantes. Uma perspectiva particular sobre o evento ou situação é imediatamente criada, e essa perspectiva gera um olhar negativo ou de oposição sobre o que está ocorrendo. Aqueles envolvidos não podem mais manter uma perspectiva única (simples) e observar a situação a partir dela. Torna-se impossível ter em mente uma única perspectiva. Fica claro para nós que as coisas não são tão simples como pensamos, nós somos levados a nos afastar das respostas fáceis, em direção a uma crescente complexidade de resposta.

A ironia opera em diversos níveis no teatro-drama. Pode funcionar como um efeito irônico dentro da estrutura de uma peça, e como uma estrutura dramática que é, em si mesma, irônica. Cada pequena ironia é um sintoma de uma ironia mais ampla. Em grandes obras, a ironia opera em vários níveis, da estrutura à fala individual, e está refletida em todo o imaginário, símbolos, e traços das personagens. As peças de Brecht são ilustrações dessa complexidade de operação e o efeito brechtiano de alienação é uma forma extrema de distanciamento irônico. Seus personagens voltam as costas às implicações de suas ações, e em seu lugar os espectadores se dão conta das ironias fundamentais do texto na forma de uma contínua contradição. As ironias em Mãe Coragem começam no título, e são evidentes em cada aspecto da peça - "Não me diga que a paz foi quebrada, exatamente agora que comprei todos estes suprimentos!"

A ironia no teatro funciona ao tomarmos um enquadramento familiar ou um contexto social, apresentando uma variação ou distorção de atitude ou comportamento costumeiro. Paradoxalmente, a violação da norma não é apresentada, mas suprimida. Não é nunca explicitada. Por exemplo, casamentos arranjados, encontros pela internet, e bancos de dados do governo já existem. Em um drama sobre um programa governamental onde todos os casamentos são arranjados e parceiros são escolhidos via computador, a estrutura dramática é em si irônica. A norma violada - o valor das ligações românticas e da escolha individual - é suprimida. A ironia está em afirmar o oposto do que é acreditado socialmente. Modest Proposal, de Swift, onde os bebês irlandeses deveriam ser gerados e criados para a panela, argumenta a favor dos benefícios sociais e humanitários do canibalismo. A ironia 
acaba quando o oposto do oposto - comer crianças é errado - é explicitado. A ironia não deve ser comentada. Cada um deve entende-la, mas ninguém pode menciona-la. "A norma nunca é citada, mas sim assumida como implícita”. ${ }^{6}$

"O confronto com uma matriz alienígena revela de forma impiedosa e aguda aquilo que deixamos de ver ao seguir nossas rotinas adormecidas; as suposições tácitas escondidas nas regras do jogo são dragadas para fora. O choque bi-associativo sacode a moldura dos hábitos de pensar complacentes; o aparentemente óbvio é levado a gritar seu segredo" (Koestler, 1975:72)

A alegoria e a ironia funcionam quando projetamos costumes e instituições inaceitáveis num pano de fundo diferente. No teatro (e no drama) isto pode envolver, por exemplo, uma visita ao espaço sideral, ou uma viagem ao passado ou ao futuro. Lá, as pessoas fazem coisas diferentes e diferentes valores são aplicáveis. Podemos, então, ver nossos próprios costumes refletidos em um espelho distorcido ou numa civilização alienígena. $\mathrm{O}$ alienígena, como um observador ingênuo, vê nossas crenças, costumes e convenções sob uma nova luz e foca nossa atenção sobre os aspectos irracionais ou injustos de nosso mundo real. Em Brave New World (Admirável Mundo Novo), o Selvagem representa esta função quando contempla os barbarismos que operam no novo mundo. Anos atrás, em um processo dramático, um grupo de crianças com dez anos de idade encontrou uma alienígena de uma sociedade matriarcal, que queria aprender sobre as instituições políticas da Terra. As crianças orgulhosamente contaram a ela que o Primeiro Ministro era uma mulher. "Naturalmente", ela respondeu, "alguma vez vocês já tiveram um Primeiro Ministro homem?"

Ao se empregar uma perspectiva irônica, o objetivo é derrotar os oponentes em seu próprio campo ao aceitarem, aparentemente, suas premissas, valores e modos de argumentação, a fim de expor os absurdos que lhe são implícitos. A ironia propõe-se a aceitar seriamente o que ela não faz; a entrar no espírito do jogo do oponente para demonstrar que suas regras são estúpidas ou viciadas. É uma arma sutil porque aqueles que a usam devem ter a força imaginativa para ver através dos olhos de seus oponentes, e de se projetar em seu mundo mental. Esta tarefa de imitação requer compreensão e certa empatia. A ironia baseia-se no conhecimento do inimigo desde que se precise dele. Não se está meramente observando o inimigo, mas reconhecendo que se carrega consigo pelo menos alguns de seus aspectos.

Os personagens mais irônicos incorporam este paradoxo. Falstaff é uma concepção gloriosamente irônica. Ele incorpora seus vícios e une forças com suas vítimas, não sendo um mero hipócrita como Tartufo. Loucura e vilania são necessárias se queremos reconhecer sabedoria e virtude. Azdak, o juiz de O Círculo de Giz Caucasiano, é um exemplo da co-existência da justiça e da corrupção. Quando a ironia de caráter e a ironia de situação coexistem, elas se fortalecem uma a outra. 
O bom drama não é nunca meramente conflito, mas sim conflito informado pela necessidade irônica. Quando essa necessidade definha, a peça se tornará menos dramática. Em grandes peças, a oposição surge a toda hora. Isto também é verdade para o drama empregado na educação, onde a antecipação irônica pode fornecer um enquadramento a ser explorado. O reverso do que esperamos ou tememos está para acontecer. Por exemplo, numa peça anos atrás em Melbourne, sobre o retorno de um grupo de astronautas 20 anos após terem sido dados como mortos, eles assistiram um vídeo sobre suas famílias, antes de terem partido. A comemoração familiar pela formatura do filho hoje, é interrompida pelo anúncio, pelo rapaz, de que iria seguir os passos do pai e tornar-se astronauta. Houve uma sensação imediata de repetição da tragédia.

\section{As Vantagens da Ironia}

A ironia é sempre velada, implícita, convidando à interpretação e ao julgamento. A primeira vantagem em se usar a ironia na promoção de encontros dramáticos, quer no palco quer no teatro-educação, é que ela provoca uma resposta ativa nos participantes e nos espectadores. Nossa satisfação ao nos depararmos com a ironia surge ao se seguir a trilha de uma lógica complexa e com suas próprias regras e pontos de partida. É esta busca que torna a ironia um grande caminho para a interpretação.

Umberto Eco definiu as peças de Brecht e Chekhov como “obras abertas”, e esta expressão é útil para descrever o funcionamento da ironia no processo dramático. Obras abertas, aquelas que oferecem ao ator e ao espectador "um trabalho a ser completado", objetivam estimular os mundos interiores destes intérpretes, de forma que tracem dentro deles respostas mais profundas, espelhando as ressonâncias da situação dramática. Brecht e Chekhov, que parecem tão diferentes em cada aspecto de suas obras, eram ambos grandes irônicos. A consciência que seus personagens não atingem é transferida para o público, que é ativado por este reconhecimento. Do mesmo modo, a "obra aberta" no processo educacional permanece aberta, a ser completada, objetivando ativar os participantes e evocando uma resposta mais profunda.

Ao "ler" as declarações ou pontos de vista irônicos que encontramos no drama, nós estamos lidando com o caráter e os valores, e fazendo isto nossas convicções mais profundas são trazidas à consciência.

\section{A Natureza do Mundo Irônico}

O universo da ironia dramática está permanentemente em movimento (impossível determiná-lo ou fixá-lo). Uma vez que o método envolve a seleção e distorção de características particulares, o mundo torna-se inevitavelmente grotesco e deformado. Ao estabelecer um mundo dramático irônico, os aspectos selecionados para distorção, como aqueles escolhidos pelo cartunista, serão provavelmente negativos, uma vez que o método requer exagero e 
simplificação. Mas isso traz outra vantagem para o professor de teatro. A ironia remove, imediatamente, as limitações do naturalismo. Ela expõe as qualidades formais da obra, permitindo experimentar abordagens tais como o surreal, o absurdo, a alegoria, a paródia e outras possibilidades estilísticas. "A ironia destrói a ilusão da autenticidade e torna palpável o convencional da arte" 7

O fato de que o mundo irônico favorece o absurdo ou o surrealismo não limita sua eficácia. Como acentua Vygotsky, ao criarmos tais mundos, estamos usando nosso intelecto com a finalidade de nos tornarmos especialistas nas leis que governam o mundo real. Como crianças deliciadas com a experiência da fantasia ou da fábula, Vygotsky alega que encontrar tais mundos salienta e desperta nossa percepção da realidade: "A fim de perceber a arte, nós precisamos contemplar simultaneamente a situação verdadeira das coisas e seu desvio desta situação. Os absurdos são ferramentas que a criança usa para compreender a realidade. A realidade é forjada a partir do estabelecimento e da destruição das contradições".

No teatro podemos observar o estabelecimento e a destruição de contradições através do uso de uma abordagem irônica. Ao criar um mundo irônico, a ênfase estará mais na situação do que no personagem. A preocupação tem menos a ver com o passado, com motivações, com memórias, do que com o confronto das possibilidades da situação corrente. O que há para se fazer? Que possibilidades permanecem num mundo criado dessa maneira? Justapor imagens, sem fazer declarações a respeito de seus relacionamentos, é parte do método irônico. Toda circunstância externa à criação deste mundo irônico é tratada com grande economia - como um conjunto abstrato, comportando somente os itens indispensáveis para a ação e aqueles que criam uma situação existencial reveladora para os personagens. Seja o que for que a gente precise saber mais, o drama irá contar.

Mas a base do teatro está na ação, não na percepção da ironia. Atos produzem atos contrários, não apenas atos aprofundados. O potencial da situação dramática é um paradoxo em sua criação. Os melhores dramas são estudos sobre a discrepância terminal - o pior do pior dos piores. O destino dos envolvidos no drama é tão impossível quanto possível. ${ }^{9}$

A ironia infunde a força de gravidade de uma peça - dramaturgos jogam seus personagens num campo de força do Absoluto. Há uma "fatalidade interna" - o que vai em frente como A retorna como não-A. O "nobre Macbeth" torna-se um "açougueiro morto". O rei Lear, cujo propósito inicial era "deixar de lado todos os cuidados", morre com sua filha morta nos braços. Essa é a ironia do momento estratégico da reversão. No teatro, tal momento pode ser o reconhecimento efetuado pelos humanos, na peça de Chapeuzinho Vermelho, da inteligência superior e da humanidade dos lobos. ${ }^{10} \mathrm{~A}$ ironia é significante porque sua presença ou ausência não muda nada no texto, exceto seu significado fundamental.

\section{Conclusão}

Quando escolhemos um pré-texto ${ }^{11}$ irônico para deslanchar um processo dramático, nós promovemos uma resposta ativa nos participantes, levando-os a decodificar a agenda oculta da situação, desenvolvendo uma postura de oposição e descobrindo suas próprias soluções. Irão mover-se do caminho da rejeição e da alienação para o da interpretação. Uma 
das maiores vantagens para o professor de teatro é que, ao adotar uma abordagem irônica, uma contradição geradora, fará o trabalho imediatamente ir além dos limites do role-play instrumental. Qualquer qualidade didática direta é também obscurecida pela ambigüidade da abordagem. É importante, como Freire enfatiza ao discutir o uso de qualquer tipo de contradição geradora em sala de aula, que a abordagem não seja explícita ou enigmática em excesso:

"A primeira (a explícita) pode degenerar em mera propaganda, com nenhuma decodificação real a ser feita além de declarar o conteúdo óbvio pré-determinado. A última (a enigmática) corre o risco de parecer um quebra-cabeça ou um jogo de adivinhação". ${ }^{12}$

Uma perspectiva irônica que mantenha equilíbrio entre o explícito e o implícito distorce e subverte o tipo de valor errôneo mas limitado dos papéis, como comumente são interpretados no teatro. Esse é um bom exemplo de método pedagógico básico, construindo na urgência instintiva do aluno um fazer o oposto ao que é proposto pelo professor.

Vygotsky (1971) considerou a arte "uma abordagem dialética para construir a vida", e o mesmo pode ser dito sobre o teatro, particularmente aquele que opera através da ironia. A impressão dialética surge da presença simultânea de uma realidade social ou histórica em nossas cabeças, como participantes ou espectadores, e seu reflexo no espelho distorcido do mundo dramático. Através de situações dramáticas irônicas descobrimos o absurdo do familiar e a familiaridade do absurdo. Como líderes, as escolhas que fizermos de um pré-texto dramático irão depender não apenas de nossos objetivos, mas também de nossas predileções - as "preferências instintivas" que dão ao nosso trabalho a sua direção e sinceridade.

Kenneth Burke (1969) alega que não podemos usar a língua com maturidade até que estejamos espontaneamente à vontade ao tratar com a ironia. Eu acredito que isso também seja verdadeiro para com a ironia no teatro. Nós não estaremos completamente à vontade com o teatro enquanto não possamos empregar a ironia espontaneamente, para distanciar, para apontar absurdos, para o desafio de aceitar normas, para desfamiliarizar nossas rotinas sociais e políticas opressivas, para levar o grupo à comunidade, e para energizar os participantes na busca de soluções eficazes.

\section{Notas}

\footnotetext{
${ }^{1}$ Process Drama, Drama, ou Drama in Education, também conhecido pela sigla DIE, equivale à forma teatral brasileira conhecida como Teatro-Educação ou Teatro na Educação, e refere-se a processos dramáticos realizados no contexto escolar, usualmente através do desenvolvimento de episódios dramáticos, cada qual no espaço e tempo semanal da disciplina Educação Artística ou Teatro na Escola. Nota da Tradutora.

${ }^{2}$ Milan Kundera (1986), The Arts of the Novel . Nova York: Grove Press, p. 23.

${ }^{3}$ Brecht, B. (1966) Brecht on Theatre. New York: Hill and Wang, p. 86

${ }^{4}$ Booth, op. cit., p. 92.
} 
${ }^{5}$ Bolton, G. (1979) Towards a Theory of Drama in Education. London, Longman.

${ }^{6}$ Umberto Eco (1986). Travels in Hyper-reality. London, Pan Books, 272-273.

${ }^{7}$ B. M.Ejxenbaum, "Henry and the Theory of the short story", in Readings in Russian Poetics, ed. L. Matejka and K. Pomorska (Ann Arbor, Mich: University of Michigan Press, 1978), p. 255.

${ }^{8}$ L. Vygotsky (1971) The Psychology of Art. (Cambridge, MA: The MIT Press).

${ }^{9}$ Bert O. States (1994) The Pleasure of the Play (Ithaca/NY: Cornell University Press), p. 71

U18 - Dezembro 2006 - Nº 8 